\title{
Working artefacts: ethnomethods of the prototype
}

\begin{abstract}
This paper follows recent science studies in theorizing information technologies as socio-material configurations, aligned into more and less durable forms. The study of how new technologies emerge shifts, on this view, from a focus on invention to an interest in ongoing practices of assembly, demonstration, and performance. This view is developed in relation to the case of the 'prototype', an exploratory technology designed to effect alignment between the multiple interests and working practices of technology research and development, and sites of technologies-in-use. In so far as it is successful, the prototype works as an exemplary artefact that is at once intelligibly familiar to the actors involved, and recognizably new.
\end{abstract}

KEYWORDS: Information technologies; science and technology studies; ethnomethodological studies of work; accountability; innovation; research and development

Drawing on the somewhat unlikely pairing of the writings of Niels Bohr and Michel Foucault, Karen Barad (1998) develops an account of technologies as material and discursive practices, combined in ways that constitute durable objects. With the help of Bohr's concept of the 'apparatus' of observation, Barad aims to extend Foucault's investigations into the materialization of human bodies to include the question of how nonhuman objects come into being. In the process she contributes to a growing corpus of writings within science and technology studies that address the question of how new objects are configured in and through technoscientific practice. ${ }^{1}$ Technologies appear in these investigations as socio-material apparatuses that align themselves into more and less coherent and durable forms. Viewed in this way, the study of how new technologies emerge shifts from a focus on invention, understood as a singular event, to an interest in ongoing practices of assembly, demonstration, and performance. The shift from an analysis in terms of form and function to a performative account, moreover, carries with it an orientation to the

British Journal of Sociology Vol. No. 53 Issue No. 2 (June 2002) pp. 163-179

(c) 2002 London School of Economics and Political Science ISSN 0007-1315 print/1468-4446 online

Published by Routledge Journals, Taylor \& Francis Ltd on behalf of the LSE

DOI: $10.1080 / 00071310220133287$ 
multiplicity of technoscience objects or, to put it differently, to the achieved nature of objective singularities (see also Law 2002). Commodities more particularly, understood as objects of economic value however accrued, circulate in 'regimes of value' operative in specific temporal and geographic locales (Appadurai 1986: 4). At the same time, objects take their shape and meaning not in any single location but through their incorporation across diverse milieu. Making technologies is, in consequence, $a$ practice of configuring new alignments between the social and the material that are both localized and able to travel, stable and reconfigurable, intelligibly familiar, and recognizably new.

For sociology, technologies-in-the-making afford an opportunity to investigate the imaginative and practical activities through which sociomaterial relations are reproduced and transformed. This paper recounts a particular case of new technology making within a context explicitly dedicated to that enterprise; that is, an industrial research centre (Xerox PARC) chartered to invent new computer-based artefacts. ${ }^{2}$ Before turning to the specifics of the case, we briefly review the argument for a view of technologies as alignments of material and discursive practice, with a focus on technologies that incorporate practices of coding and classification. Against that background, we introduce the prototype as an artefact with particular performative characteristics within the work of new technology design. The case that follows, involving the development of a research prototype aimed at the organization of documentary records, both enacts and expands the view provided by previous studies. We conclude with some reflections on the implications of an ethnomethodological stance toward technological objects, and on prototype technologies as performative artefacts that work in particular ways, for a sociology of work, technology and organizations.

\section{TECHNOLOGIES OF ACCOUNTABILITY}

The accountable reproduction of social order, in and through ordinary activities, is a central theme within ethnomethodological studies of work, science and technology (see for example Garfinkel 1986; Button 1993; Lynch 1993; Garfinkel 1996; Heath and Luff 2000). The term 'accountability' within ethnomethodology references a basic aspect of the moral and practical grounding of everyday activity. That is to say, our viability as members of the social world turns on our ability to make sense of the actions of others, and to make ourselves sensible to them; what Garfinkel (1967: vii) has named the 'observable-reportable' character of practical reasoning and action (see also Lynch 1993: 14-5). In this respect, accountability means just that we hold each other responsible for the intelligibility of our actions in relation to the circumstances at hand. At the same time, we are also located within specific, historically constituted orders of 
accountability, administered through more and less explicit regimes of organizational and institutional control.

Ethnomethodological studies of work orient us as well to the pervasive presence of technologies of classification, as ordering devices for organizational accountability. Of particular interest in the case that follows is the longstanding organizational practice of record keeping. As technologies of accountability, organizational records work both in the ongoing accomplishment of mutually intelligible concerted action and in the retrospective reconstruction of defensible organizational histories (see also Yates 1989, Smith 1990, Bowker 1994). The advent of digital media has brought new currency to the question of the specific materialities of documentary records; materialities that quite literally (and unexpectedly) matter for the ongoing reproduction of organizationally relevant histories and contemporary practices.

\section{THE PROTOTYPE AS A RESOURCE FOR SYSTEM DESIGN}

The project that we report below is located within this larger enterprise of research and development regarding new digital media, and it is here that the particularities of the prototype become relevant. A persistent trouble for professional designers ${ }^{3}$ of computer-based information systems is the reported failure of their products to deliver on promised benefits, either to the economy of organizations or to the working practices of organization members. Among the various assessments of the source of this trouble, a central characterization is that designers fail to achieve an adequate understanding of 'user needs', taken as more and less precisely stated requirements for what a given system should do. Much ink has been spilled in the professional literature on this topic, and proposals abound for the introduction of processes, methods, and schemes of assessment developed to evaluate and improve upon existing design practice.

Calls for greater user involvement in the design process as a possible remedy to the problem of inadequate identification of user needs first appear in the literature in the late 1960s (Grønbaek 1991: 8). Somewhat more recently, software engineering practice has followed earlier forms (mechanical and electrical) in recognizing the difficulties of building technologies relying solely on paper-based descriptions. ${ }^{4}$ A range of devices for embodying technology ideas into artefacts, intended to serve as a resource for subsequent system development, appear in the late 1970s. The involvement of users in design and a reliance on prototyping as a design strategy first come together in the late 1980s, most explicitly in the context of trade union-sponsored research in Scandinavia. ${ }^{5}$

While much of the literature on user involvement and system prototyping follows traditional lines in offering normative models for organizing professional conduct, the more radical initiatives comprise a reorientation as well away from methods of formal analysis as core resources for system 
design (Grønbaek op cit.: 9). Various literary devices continue to have their uses, but the centre of gravity shifts from the production of system specifications and various other abstract renderings of system functionality, to the prototype and associated practices as directly embodying the design. ${ }^{6}$ General methods of prescriptive representation are displaced by specific projects under this strategy, based in and contributing to reports on a repertoire of techniques, along with reflections on the significance of past experiences for future work.

A second shift toward a more radical reconstruction of traditional design practice turns on basic assumptions regarding the status of 'user needs'. For many if not most advocates, prototyping represents a strategy for 'uncovering' user needs, taken as already existing but somehow latent, unarticulated or even unrecognized by practitioners themselves. The project then is to elicit these pre-existing attributes from the prospective user, to express them precisely and thereby to make them available for use by professional system designers. An alternative position, adopted in the case reported here, is that prototyping practice simultaneously recovers and invents work requirements and technological possibilities, that each make sense in relation to the other. Statements of what users need or what a system should do are characterized by the kind of 'specific vagueness' (Garfinkel 1996) that holds for any formulation apart from its practical elaboration in situ. At the same time, particular prototyping projects are accountable to extended networks of professional relations and concerns, both technological and otherwise. The project of constructing a prototype on this view affords possibilities for respecifying a relevant form of work in and through the act of building a new artefact; one that simultaneously reconfigures the work's practice while maintaining its accountability to relevant professional and organizational constituencies.

Related to the status of user requirements are assumptions regarding who actually designs computer artefacts, and when. Forty (1986) calls for closer critical examination of the economic and ideological aspects of design, which he argues are obscured by the focus on functional and aesthetic considerations. In particular, he points out that 'design came into being at a particular stage in the history of capitalism and played a vital part in the creation of industrial wealth' (ibid.: 6, see also Noble 1977). One characteristic of the history of design has been its alignment with the emergence of the professions, as making things has come to be more and more the exclusive provenance of those with credentials to do so, while things made are correspondingly more esoteric. System development discourse traditionally assumes that computer systems are designed by computer professionals and that the design is complete following its final implementation, at which point the system is handed over to its intended users for use. Recent challenges to this view from within the research and development community point to the fallacy of taking computer professionals as exclusive designers, either as a description of current practice, or as a desideratum for future practice (see for example Clement 1993, Nardi 1993). 
Recent experiments in various forms of participatory or co-operative design have aimed, among other things, to trouble the boundary between design and use, making it clear that however much the two may name distributions in a professional division of labour, the realities of technological practice belie the distinction. Heath and Luff, for example, describe the 'ecological flexibility' or 'micro-mobility' of the paper patient record in medical work, including 'the ability to ongoingly configure the artefact with regard to the shifting demands of the activity' (1998: 307, see also Hughes, et al. 1993). They describe the delicate choreography through which physicians and patients orient to the production and use of medical records in the course of a consultation, and draw attention to complications introduced by the shift from paper to electronic media. Ongoing practices of design-in-use of computer-based systems include managing the contingencies involved in simply incorporating an artefact into an existing social/technical infrastructure, and appropriating it effectively into specific sites of practice. Design-in-use also includes the varying degrees of lay and professional re-configuration and customization typical of any actual technology implementation. Prescriptively, affiliations with other movements toward more democratic, participatory forms of design emphasize the value of crossing professional boundaries and reworking relations of technology production (Suchman 1994). The aim of these initiatives is a radical refiguring of relations of design and use, including both recognition of the extent to which design continues in use, and reformations of practices of professional design.

It is in this latter context that proposals for a 'co-operative prototyping' practice arise. Acknowledging the distinct social worlds, shop floors and associated knowledges of computer professionals and the various other practitioners who use computer artefacts, the call is none the less for the creation of occasions on which more direct and intensive forms of codevelopment can occur. Our own work aligns strongly with this project, on the grounds that technological knowledge, while necessary, is not sufficient for the development of useful computer artefacts. In constructing an artefact co-operatively, technological and other shop floor knowledges are exchanged between computer professionals and other workers. As importantly, parties respecify, in and through the prototyping process, their own work's practices.

Our concern in the remainder of this paper is the relation between the work of making technology prototypes, and how prototypes are made to work as occasioned practices of technology design and use (see also Button and Sharrock 1994). Technology prototyping as we have practiced it involves configuring socio-material ar tefacts - including working practices, hardware and software - in a way that constructs a partial alignment across the heterogeneous shop floors of industrial research and development on the one hand, and various sites of work and technology use on the other. This alignment, in turn, relies upon a series of what Harold Garfinkel has named praxiologically valid courses of instructed action; that is, occasioned 
demonstrations of just what it is that we are up to, here and now (1996: 9.). In what follows we explore a view of prototyping as mutual engagement in such courses of instructed action, across sites of technology development and use. We see 'the prototype', conventionally taken as a mediating artefact in designer-user interactions, as constituted in and inseparable from those interactions.

\section{THE SETTING}

As researchers at Xerox PARC we stood as well in the position of designers, charged with bringing ethnographic and ethnomethodological insights to the invention of new, document-related information technologies. From this standpoint we entered into collaborative projects with organizations positioned as prospective customers (or more specifically, with organization members who might actually use the technologies that we codesigned). As a case in point, in what follows we describe a project conducted in the late 1990s at the headquarters of a state Department of Highways (called here 'the Department') on the West Coast of the USA. For approximately two years we engaged in a collaborative research effort with engineers at the Department charged with the design of a bridge, scheduled for completion by the year $2004 .^{7}$

The focus of our prototyping efforts with members of the bridge project was a collection of their documents called the project files (see Plate I). The project files fall within the class of document collections recognized by science, technology and organization studies for their sociological interest, as central elements in the production of social order. Within the Department, every engineering team is responsible for maintaining a cumulative archive of all documents taken to be relevant to a particular project. This includes a heterogeneous assortment of letters, memos, reports, newspaper clippings, maps and the like, that together provide a documentary resource for demonstrating professional and organizational accountability. Assembled collectively (each member of the team being responsible for adding relevant documents to the files), the project files act as a shared resource during the project's course. So, for example, a question may arise as to whether or not a required permit was in fact secured for some aspect of the project, occasioning a search through the collection for correspondence documenting that and just when the permit was granted. In this respect the value of the collection is tied less to any intrinsic characteristics of the documents, knowable in advance, than to their availability with respect to an unforeseeable horizon of possible inquiries.

This aspect of the work of engineering brings us into the presence of a persistent trouble for practitioners, and a recurring interest for ethnomethodological studies; that is, the kind of situated inquiry displayed, in this case, in the twin questions 'How should this document be filed?' and 'Where is that document?' To explore these interests further, we embarked 


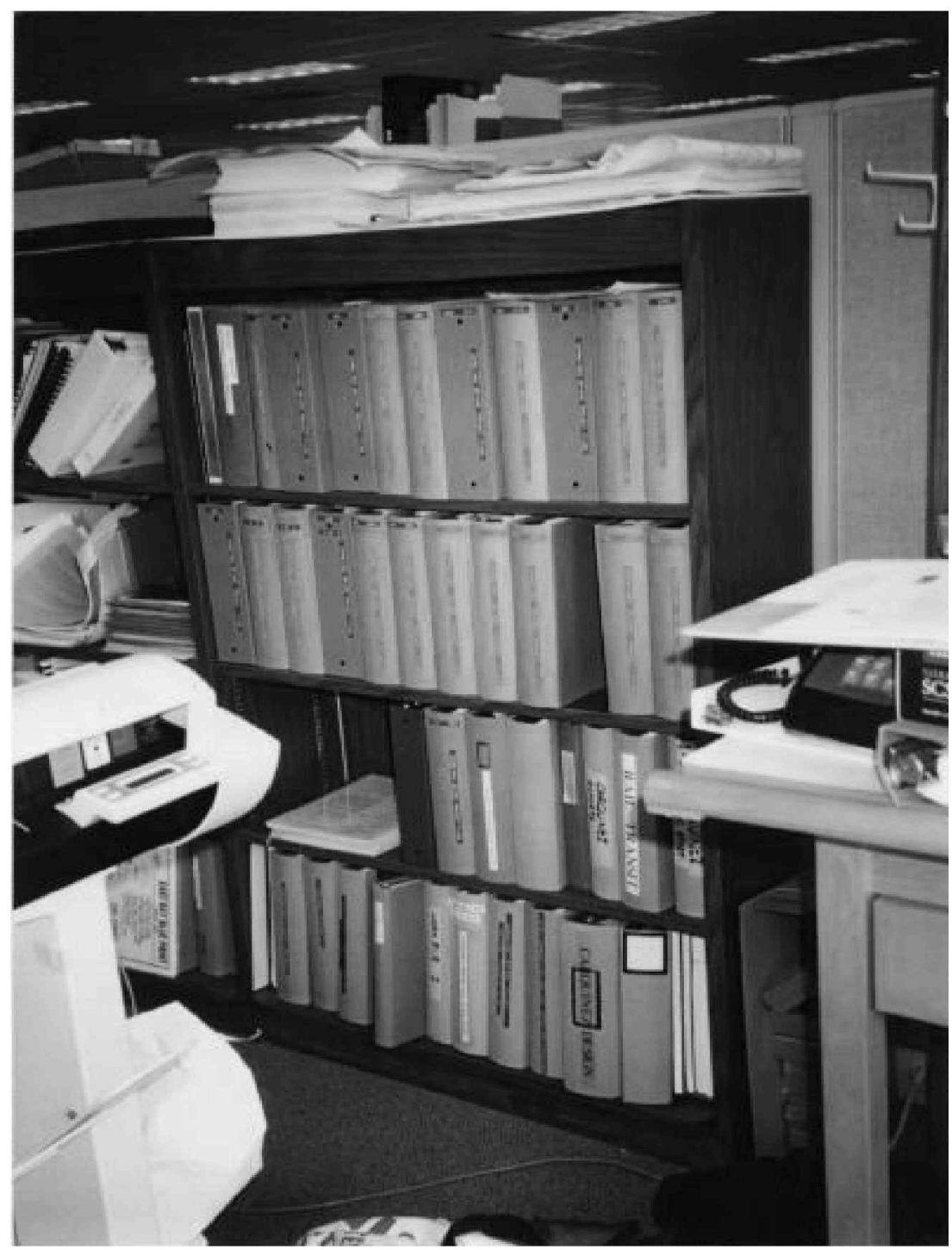

PLATE I: Project files

on a co-operative design effort with the engineering team aimed at understanding whether digital media might provide new and useful ways of accessing their collection. More specifically, this involved understanding just what would be required to move their project files, currently kept on paper in three ring binders, into an electronic, computer-based repository with a rich search interface. To develop that understanding, in turn, meant engaging in a course of mutual learning aimed at recovering the work of 
the project files and their relevance to our respective worksites and work practices.

\section{THE ACHIEVED COHERENCE OF THE PROJECT FILES}

The paper project files were ordered through a standardized system of categories, known as the Uniform File System or UFS, in use across all projects within the Department. The UFS as a classification scheme exhibits multiple, crosscutting interests in the documents that it orders. First, the UFS records a normal order of work, in so far as it follows a chronology of designated project phases, from Environmental impact assessment to Design to Construction. At the same time, the UFS is oriented to the kinds of objects that it orders; namely, document types that take the form of correspondence, agreements, permits, reports, public notices and the like. Each of these as well addresses particular topical relevances, for example soil testing or drainage. Finally, the files are oriented to relevant actors, including federal, state and local agencies, citizens, and the Department itself, as sources and recipients of the documents. And along with this classificatory equivocation, the project files are oriented to, on one hand, constituting a working document collection to be referenced as the occasion arises within the life of the project and, on the other hand, constructing an archival history of the project after the fact. As rendered by the Uniform Filing System, all of these various interests are flattened into a single hierarchical structure that belies their heterogeneity (see also Bowker and Star 1999).

While the Uniform Filing System promises a standardized framework to be used across the Department, its use for any actual project requires a range of ad hoc practices of elaboration and specification. As ethnomethodological studies of coding practices have made clear, far from an irony these variations in use of the UFS are essential to its operation as an effective technology of order production. We are interested in understanding the UFS therefore not as a logical system or text, but as the procedural work of document coding. ${ }^{8}$ To that end, members of the engineering team instructed us on the project files' coherence and routine troubles within their own working practices. A central trouble is one that we could describe as the persistent misalignment of the work of document filing and retrieval. By that we mean that there are two, at times incommensurable orders of activity involved. The first is the business of filing documents in accordance with the logics of the UFS. This takes the form of a kind of puzzle, involving the creation of an accountably rational, coherent fit between the UFS as a generic description and the characterization of a particular document in hand. The second is the business of finding documents, as a contingent and specifically situated inquiry, occasioned by an immediate question that arises. This latter business defies a priori logics in so far as just when and just why a particular document may become relevant, valuable, interesting and needed cannot be predicted in advance. 
The prototype that we configured and installed in the project team's workspace was made up of a scanner, designed to take paper documents and convert them to digital images, connected to a PC running software that supports viewing and manipulation of those images, as well as their conversion into 'optically character recognized', and therefore editable, online text. Latour observes that technical projects encounter not only human actors who are differently interested and aligned, but assemblages of things that may or may not be compatible one with another (1996: 57). Despite its famed flexibility, perhaps nowhere is this more true than with software. 'Compatibility', the requirement for things to work with one another, can be missing for a plethora of reasons. These range from the deliberate inclusion in one device of proprietary or 'closed' software that makes it impossible to integrate that device with others, to simple oversight on the part of developers, to historical discontinuities that leave gaps which dedicated labour (that in turn may or may not be available) is required to fill. Far from the de novo invention of a new device, configuring the prototype included identifying appropriate hardware and software, and acquiring the various pieces required through a variety of channels (purchasing and downloading from the Internet, primarily). It included as well, and essentially, designing the computational glue that would connect them together into a coherent and working whole. ${ }^{9}$

The aim for the prototype was that it should exhibit the documents in the project files in recognizably coherent, but newly flexible ways. This included novel renderings of documents that none the less made sense with reference to familiar practices. The latter included, as described above, the filing of documents in binders according to the numerical categories of the UFS. Under the existing scheme, binders were labeled and placed in order on shelves, such that searching for a document involved opening the binder for the UFS category deemed most likely and visually scanning through the documents in that binder for one that appeared relevant. The prototype in part reproduced the paper binders by providing an ordering of documents according to the UFS categorization scheme, and by supporting viewing of document images.

In other respects, however, the prototype transformed previous practices. It provided capabilities for alternative orderings of the collection not previously possible (for example, displaying all of the documents ordered by dates), enabled full text search across documents based on Optical Character Recognition, made it possible to view all pages of a document arrayed on the screen as reduced, 'thumbnail' images, and so on. At the engineering worksite, the prototype stood as a kind of developing description of how it was that engineers were interested in accessing their documents. But more than just description, the prototype offered a provisional proposal for a new working practice. It did so not simply as a matter of talk, but as a means for trying the proposal out. In response it elicited either a 


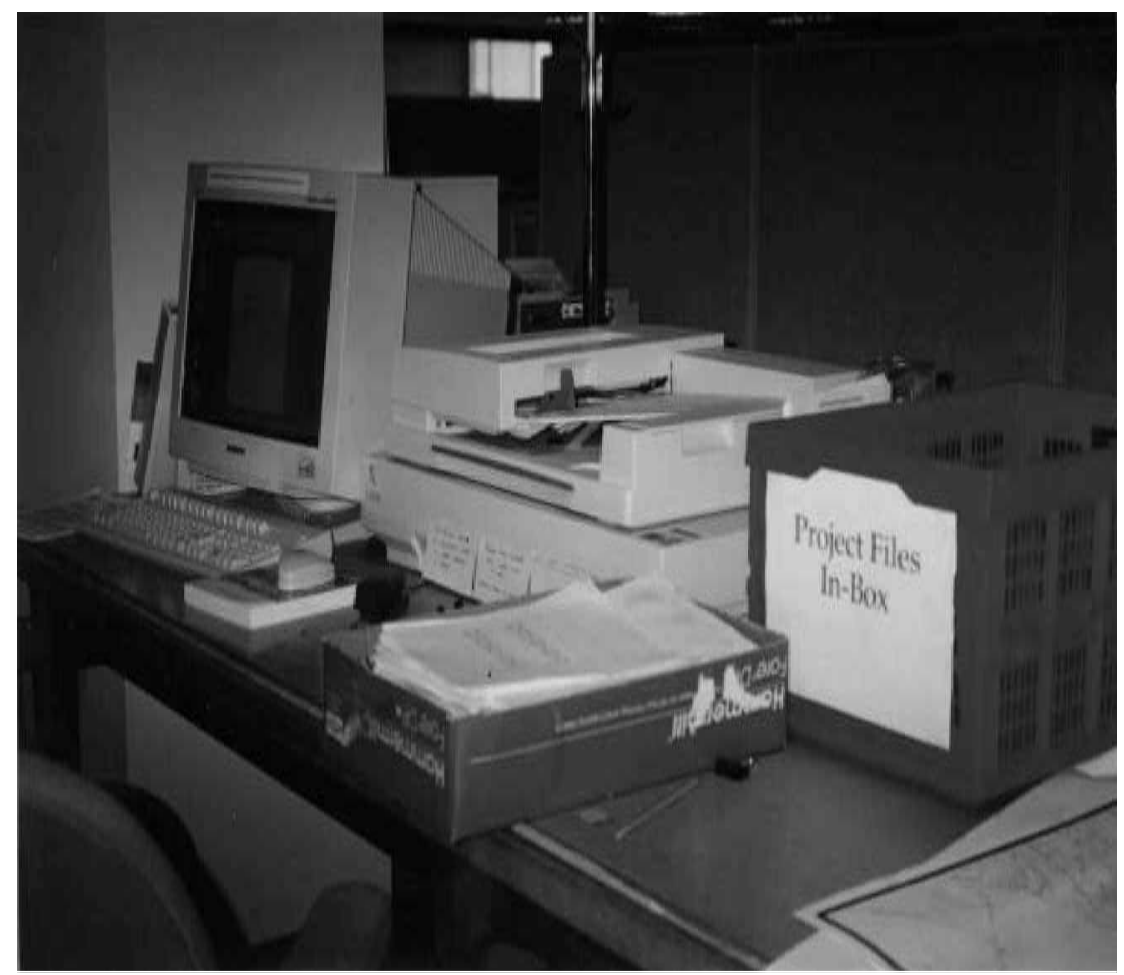

PLATE II: The prototype

'Yes, that makes sense', or an account of how it was that, in that proposal, we had missed the point. It is in this sense that prototypes perform as working artefacts; artefacts whose significance is not given in advance, but is discovered through the unfolding activity of co-operative design-in-use.

\section{DEMONSTRABLE RELEVANCES OF THE PROTOTYPE}

The multivocality of the project files prototype, as a 'material-semiotic workstation' (Bleecker 1995) whose effectiveness is reiteratively performed, is most evident on the occasion of the 'demo' or system demonstration. In standard practices of research and development, the demonstration typically occurs as a singular moment - for management during a presentation aimed at providing reassurance that money has been well spent or at securing funds for further work, for visitors on a tour, or for industry analysts on the floor of a trade show. The audience's relation to the artefact is indirect, positioned more as investor, tourist, or professional critic than as intended user. At the Department, in contrast, demonstrations migrated into trials that found their way progressively into 
everyday use. The demo/trial/working prototype incorporated materials of direct interest to its intended recipients, and was aimed at establishing the artefact's relevance and effectiveness for their everyday practice as civil engineers.

But the prototype performed on other stages as well. Beyond the demonstrable relevance of the artefact to the practices of engineering, it needed to work as an embodiment of new technological possibilities not yet available in the market. A premise of our engagement with Department engineers was our position as spokespersons for a world of 'cutting-edge technology' (see Latour 1996: 43). Our identification as such was most obviously relevant in the initial conversations with Department management, through which the project was approved and our access to the site granted. That identity derived, in turn, from our association with a wellknown research centre, and it was there that the demands and accountabilities of 'innovation' were more specifically and exactingly felt. In particular, our choice of the project files as a focus for our prototyping efforts was informed not only by the files' sociological interest, and their practical relevance to Department engineers and management, but by the possibility of aligning them with ongoing research interests 'back home'. This involved identifying the project files prototype with the category of new document technologies addressed to document storage and retrieval across paper and digital media.

Our own position as researchers meant, more specifically, that the prototype could not simply configure 'off the shelf' technologies, however ingeniously, but needed as well to incorporate emerging technologies of interest to our colleagues and the wider research community. So, for example, we worked to include new techniques of document analysis then under exploration at Xerox PARC and elsewhere. At the time of our project, the research areas of automatic text and image-based document analysis remained relatively separate from each other within the research world. Those who worked on text analysis tended to rely on standardized, exclusively textual corpora in use across the community of text recognition researchers, while those who worked on image analysis made use of other corpora made up primarily of photographic images. Techniques used in one area of research were carefully honed to optimal performance on the relevant corpora, and there was little in the way of hybrid approaches. In relation to these audiences, the project files were distinctive as a corpus in so far as many documents included both text and images on a single page, pushing on the boundaries of existing techniques and validating emerging attempts at their integration. This, combined with the overall heterogeneity of documents in the files, became a basis for positioning their digitization as a 'cutting edge' problem. At the same time, and again in some contrast to standard research corpora, the files in their heterogeneity stood as representatives of 'real world' collections. In its ability to address these characteristics of project file documents and their use, the project files prototype spoke as well as a representative of the value of the innovative 
research approach that we were interested in developing, one oriented to specific forms of work, carried out in situ and in co-operation with relevant practitioners. All of these aspects were emphasized in our accounts of the project and in demonstrations of the prototype for research audiences.

In addition to its currency as a useful artefact for civil engineering and as a research object, moreover, the prototype had to work within the context of industrial product development. Here it took on yet another character, assuming the identity of a 'multi-function' device, a machine combining scanning and printing hardware, as well as the software 'services' required to manipulate digitized document text and images in useful ways. This persona was relevant to corporate audiences interested in the role of the research centre in validating upcoming product lines already on offer from the company, and in pointing out (to both internal and external audiences) promising new directions. Along with the prototype's (re)positioning as a proto-product, the Department in these presentations became a market, specifically the 'government' or 'public sector', into which company products were and could prospectively be sold. The project files prototype to a product and marketing audience, in sum, offered a demonstration of emerging technologies directed simultaneously at general possibilities for new 'document systems', and at the needs of a particular, and recognizably important, industry sector. The prototype's multiplicity was central to the ways in which it worked as a polysemous object that could be made to speak in different voices for different audiences and, correspondingly, to its effectiveness as tool for a research and development.

\section{CONCLUSION}

We are told by Harold Garfinkel of the resonance of our project with Calvin Mooers' efforts in the 1950s to develop a document classification scheme for engineers. Mooers' problem was to provide for the coherence of texts that were specific to the work circumstances of the engineers who had to make use of them, but who could not guarantee at the time of entry of the documents into the library what their interests would be later on (see Garfinkel 1996: 14). They could not prespecify, in other words, what the interests of a given document would be at the time that they might come to be looking for it or, alternately, for what document exactly they might be looking. It is in this respect that the coherence of documents is irremediably chained to a local (in both space and time) population of readers. Similarly, for the prototype itself the question is always, and reiteratively: What have we got at this point, and what can we say about it and do with it, vis à vis the circumstances at hand? This is not to say that there is no constancy to the artefact. Rather, it is the reiteration of these questions and the construction of satisfactory answers to them that sustains its continuity.

Our version of a system for the storage and retrieval of what Mooers 
called 'locally valuable documents' stood in direct contrast to generic systems of lexical categorization aimed, for example, at the universalized populace of the World Wide Web. ${ }^{10}$ Instead it provided for the management of a small collection in multiple ways aimed at orderings, familiar and new, of relevance to collections of just this kind, just now. Ethnomethodological studies are characterized by an interest in the production and accountability of order, understood as always already present in the specificities of lived work. With this in mind, we are interested in the implications of the prototype as a specific materialization that is instructively revealing of work across multiple shop floors, that respecifies the work without delivering it as general formulations, and that exhibits the work in a form that practitioners recognize, reject, rework, and so forth. Our aim was that our prototype should exhibit new technological possibilities in ways that, through its demonstrable appreciation for members' familiar practices and its rendering of those practices, made the new possibilities praxiologically relevant to practitioners.

The work of the prototype, following Barad, was to perform as a tangible, but also provisional, apparatus - an object that reconfigured material and discursive practice in an accountably relevant way. The prototype reworked the configuration of project files as documents, categorization schemes and associated work practices into a new, screen-based workspace. But it also illuminated the coherence of technical artefacts as a contingent achievement in ways deliberately obscured in professional talk about finished products. Perhaps even more than a 'finished' artefact, moreover, the prototype's accountabilities were multiple, orienting alternately to relevances of research and innovation, product development and marketing, and effective incorporation into various fields of professional practice. In this respect the prototype worked as a reflexive probe into the practical materializations that configure new technological objects.

Ethnomethodological studies of work, technology and organizations align well, we would argue, with recent turns to the performative in social studies of science, feminist theory, and elsewhere. The common move is a shift from a view of objects and actions as pre-established and normatively determined in their significance, to an appreciation for the enacted, irreducibly relational constitution of material and social orders. At the same time, objects and actions are realized within culturally and historically reiterated fields of possibility, which afford the familiar ground of everyday experience. Within this developing theoretical frame, the prototype offers a perspicuous case of a performative artefact that works to align multiple, discontinuous social worlds. Like any technology, the prototype does not work on its own, but as part of a dynamic assemblage of interests, fantasies and practical actions, out of which new socio-material arrangements arise.

(Date accepted: February 2002)

Lucy Suchman

Dept. of Sociology

University of Lancaster, 
Randall Trigg

Global Fund for Women

San Francisco, CA.

and

Jeanette Blomberg

Department of Work Science

Blekinge Institute of Technology

Sweden

\section{ACKNOWLEDGMENTS}

An earlier version of this paper was presented at the 1998 annual meetings of the American Sociological Association, in a session titled 'Ethnomethodology: Hybrid studies of the workplace and technology', organized by Harold Garfinkel. We thank him for his inspiration, and his enthusiastic support for our work. Thanks as well to Christian Heath and Graham Button for helpful comments.

\section{NOTES}

1. The term 'technoscience' is a useful neologism, first coined by Latour (1987), to signal the growing inseparability of science and technology. Barad's work is located within feminist science studies, where the question of how things come 'to matter', in Judith Butler's (1993) punning of that word is a central interest. An exemplary text is Haraway's wide-ranging discussion of 'material-semiotic' practices in Modest Witness (1997), and similar concerns characterize studies investigating reproductive technologies as new sites of 'ontological choreography' (Cussins 1996). See also the papers collected in Edwards' et al. (1993), and Franklin and Ragone (1998). The focus in this paper is on practices of 'research and development' as explicit projects of new technology building. Other relevant investigations include Garfinkel, et al. (1981), Lynch (1985), Collins (1992 [1985]), Shapin and Schaffer (1985), Law (1987), Traweek (1988), Clarke and Fujimura (1992), Goodwin (1994), Pickering (1995), Law (2002), Franklin (forthcoming).

2. PARC is an acronym for Palo Alto Research Center. The authors worked as researchers at Xerox PARC from the late 1970 s to the late 1990 s. Our projects involved interdisciplinary (primarily anthropology and computer science) collaborations in the design of information technologies based in an understanding of everyday practice. For more on these projects see Blomberg, et al. (1996) Suchman, et al. (1999).

3. For our present purposes we follow Grønbaek (1991) in using the general term 'designer' to refer to a range of practitioners including those positioned as researchers, systems analysts, programmers and developers. While these category distinctions and the associated problematics of identity and working divisions of labour are worthy of analysis in their own right, they are not our focus here.

4. The fact that the limits of literary devices was not immediately obvious in the case of software engineering is presumably a reflection of the extent to which software production was viewed as a matter of logic, mathematics and code-writing rather than as the construction of things. For more on the relations of mechanical, electrical and software engineering senses of the term 'prototype', and between software 
engineering and other aspects of system development, see Grønbaek (1991: 13-27).

5. For a history see Ehn (1993). Collections devoted to the topic of participatory systems design include Greenbaum and Kyng (1991), Muller and Kuhn (1993), Schuler and Namioka (1993).

6. This is not to say that the prototype simply becomes an early version of the delivered product. Debate continues within the field on the question of just what the status of the prototype should be, beginning with Brooks' famous dictum that 'The management question is ... not whether to build a pilot system and throw it away. You will do that. The only question is whether to plan in advance to build a throwaway, or to promise to deliver the throwaway to customers' (1975: 116, original emphasis). While Brooks assumes a clear distinction between a system and its descendents, we see a more complex and dynamic series of more and less substantial transformations. The relation between prototype and final product is hence both more problematic and more continuous in our view. None the less, we take the basic spirit of Brooks' dictum - iteration - as crucial. See also Floyd et al's notion of 'evolutionary development' (1989).

7. Our research group at Xerox PARC, named Work Practice and Technology, was founded on the premise that studies of existing working practices, in combination with co-operative prototyping, can provide a generative basis for the development of new information artifacts. We approached the Department with the proposal that we engage in a course of collaborative research, during which no money would change hands but at the end of which we would each be in a stronger position. Specifically, we argued that while we could not deliver a fully implemented, organization-wide system at the end of the project, we could commit that they would be better equipped to plan their own technology strategy. Through our efforts they would develop a deeper understanding both of the state of the art in document storage and retrieval, and of their own requirements with respect to new document management technologies. We in turn would deepen our theoretical and practical appreciation for relations of work and technology, and for the possibilities of alternative, participatory and work-oriented design practices. This approach, adopted across a series of projects during the 10 years of our research group's existence, opened up a new space not available either in traditional research venues, or in relations of technology vendors and their customers. For more on the project see Suchman (2000 a, b).

8. Document coding and search comprise a form of what Law and Lynch (1990) have termed 'literary language games'. The work of coding documents, while not treated in detail in the present paper, is itself a practice wor thy of extensive investigation. For further analyses of the work of coding see for example Garfinkel (1967, chapter 6), Goodwin (1994, 2000), Suchman (2000c), Heath and Luff (2000, chapter 2) and the paper by Law and Lynch mentioned above. For a wideranging consideration of the problematics of classification systems see Bowker and Star (1999).

9. The interdisciplinary character of our research team meant that we were able to engage in these forms of technological assemblage directly; more specifically through the work of Randall Trigg, a computer scientist.

10. Note that despite the rhetorics of generality and globalization, any actual instance of search over the World Wide Web is itself as specific and local as those done with smaller-scale, more specialized collections.

\section{BIBLIOGRAPHY}

Appadurai, A. 1986 'Introduction: commodities and the politics of value' in A. Appadurai (ed.) The Social Life of Things: commodities in cultural perspective, Cambridge: Cambridge University Press.

Barad, K. 1998 'Getting Real: Technoscientific Practices and the Materialization of Reality', Differences: A Journal of Feminist Cultural Studies 10(2): 88-128.

Bleecker, J. 1995 'Urban Crisis: Past, Present and Virtual', Socialist Review 24 (1-2): 189-221. 
Blomberg, J., Suchman, L. and Trigg, R. 1996 'Reflections on a Work-Oriented Design Project', Human-Computer Interaction 11: 237-65.

Bowker, G. 1994 Science on the Run: Information management and industrial geophysics at Schlumberger, 1920-1940, Cambridge, MA: MIT Press.

Bowker, G. and Star, S. L. 1999 Sorting Things Out: Classification and its Consequences, Cambridge, MA: MIT Press.

Brooks, F. 1975 The Mythical Man-Month: Essays on Software Engineering, Reading, MA: Addison-Wesley.

Butler, J. 1993 Bodies that Matter: On the discursive limits of 'sex', New York: Routledge.

Button, G. (ed.) 1993 Technology in Working Order: Studies of work, interaction and technology, London: Routledge.

Button, G. and Sharrock, W. 1994 'Occasioned Practices in the Work of Software Engineers', in M. Jirotka and J. Goguen (eds) Requirements Engineering: Social and Technical Issues, London: Academic Press.

— 1998 'The Organizational Accountability of Technological Work', Social Studies of Science 28(1): 73-102.

Clarke, A. and Fujimura, J. 1992 The Right Tools for the Job: At work in Twentieth Century life science, Princeton, NJ: Princeton University Press.

Clement, A. 1993 'Looking for Designers: Transforming the 'Invisible' Infrastructure of Computerised Office Work', $A I \mathcal{E}$ Society 7: 323-44.

Collins, H. M. 1992 Changing Order: Replication and induction in scientific practice, Chicago: University of Chicago Press [first published in 1985].

Cussins, C. 1996 'Ontological Choreography: Agency through objectification in infertility clinics', Social Studies of Science 26: 575-610.

Edwards, J., Franklin, S., Hirsch, E., Price, F. and Strathern, M. (eds) 1993 Technologies of Procreation: Kinship in the age of assisted conception, Manchester and New York: Manchester University Press.

Ehn, P. 1993 'Scandinavian Design: On Participation and Skill', in D. Schuler and A. Namioka (eds) Participatory Design: Principles and Practices, Hillsdale, NJ: Erlbaum. Floyd, C., Mehl, W., Reisin, F., Schmidt, G. and Wolf, G. 1989 'Out of Scandinavia: Alternative Approaches to Software Design and System Development', HumanComputer Interaction 4(4): 253-350.

Forty, A. 1986 Objects of Desire: Design and society from Wedgewood to IBM, New York: Pantheon.

Franklin, S. forthcoming Life Itself: Reproductive politics in the new millenium, Minneapolis: University of Minnesota Press.

Franklin, S. and Ragone, H. (eds) 1998 Reproducing Reproduction: Kinship, power and technological innovation, Philadelphia: University of Pennsylvania Press.

Garfinkel, H. 1967 Studies in Ethnomethodology, Englewood Cliffs, NJ: Prentice Hall.

— (ed.) 1986 Ethnomethodological Studies of Work, London: Routledge.

1996 'Ethnomethodology's Program', Social Psychology Quarterly 59(1): 5-20.

Garfinkel, H., Lynch, M. and Livingston, E. 1981 'The Work of a Discovering Science Construed with Materials from the Optically Discovered Pulsar', Philosophy of the Social Sciences 11: 131-58.

Goodwin, C. 1994 'Professional Vision', American Anthropologist 96: 606-33.

2000 'Practices of Color Classification', Mind, Culture and Activity 7(1 and 2): 19-36.

Greenbaum, J. and Kyng M. (eds) 1991 Design at Work: Cooperative Design of Computer Systems, Hillsdale, NJ: Lawrence Erlbaum Associates.

Grønbaek, K. 1991 Prototyping and active user involvement in system development: Towards a cooperative prototyping approach. Ph.D. dissertation, Computer Science Department, Aarhus University, Denmark. Haraway, D. 1997 Modest_Witness@ Second_Millenium:.FemaleMan @_Meets_ Oncomouse $^{\mathrm{TM}}$, New York: Routledge.

Heath, C. and Luff, P. 1998 'Mobility in Collaboration', Proceedings of the ACM Conference on Computer-Supported Cooperative Work. New York: Association for Computing Machinery.

2000 Technology in Action, Cambridge: Cambridge University Press.

Hughes, J., Randall, D. and Shapiro, D. 1993 'From Ethnographic Record to System Design', Computer-Supported Cooperative Work 1(3): 123-41.

Latour, B. 1987 Science in Action: How to follow scientists and engineers through society, Cambridge, MA: Cambridge University Press. 
1996 Aramis or The Love of Technology, Cambridge, MA: Harvard University Press. —_ 1999 Pandora's Hope: Essays in the reality of science studies, Cambridge, MA: Harvard University Press.

Law, J. 1987 'Technology and Heterogeneous Engineering: The case of Portuguese Expansion', in. W. Bijker, T. Hughes and T. Pinch (eds) The Social Construction of Technological Systems, Cambridge, MA: MIT Press.

- 2002 Aircraft Stories: Decentering the object in technoscience, Durham and London: Duke University Press.

Law, J. and Lynch, M. 1990 'Lists, Field Guides, and the Descriptive Organization of Seeing: Birdwatching as an exemplary observational activity', in M. Lynch and S. Woolgar (eds) Representation in Scientific Practice, Cambridge, MA: MIT Press.

Lynch, M. 1985 Art and Artefact in Laboratory Science: A study of shop work and shop talk in a research laboratory, London: Routledge and Kegan Paul.

1993 Scientific Practice and Ordinary Action: Ethnomethodology and social studies of science, New York: Cambridge University Press.

Muller, M. and Kuhn, S. (eds) 1993 'Special issue on Participatory Design', Communications of the ACM 36(4).

Nardi, B. A. 1993 A Small Matter of Programming: Perspectives on End User Computing, Cambridge, MA: The MIT Press.

Noble, D. 1977 America by Design: Science, technology and the rise of corporate capitalism, Oxford and New York: Oxford University Press.

Pickering, A. 1995 The Mangle of Practice: Time, agency and science, Chicago and London: University of Chicago Press.

Sacks, H. 1963 'On Sociological Description', Berkeley Journal of Sociology 8: 1-16.

Schuler, D., and Namioka, A. (eds) 1993
Participatory Design: Principles and Practices, Hillsdale, NJ: Lawrence Erlbaum Associates.

Shapin, S. and Schaffer, S. 1985 Leviathan and the Airpump: Hobbes, Boyle and the Experimental Life, Princeton: Princeton University Press.

Smith, D. 1990 The Conceptual Practices of Power: A feminist sociology of knowledge, Boston: Northeastern University Press.

Suchman, L. 1993 'Technologies of Accountability: Of lizards and aeroplanes', in G. Button Technology in Working Order: Studies of work, interaction and technology, London: Routledge.

1994 'Working Relations of Technology Production and Use', Computer Supported Cooperative Work (CSCW) 2: 21-39. (Reprinted in part in D. Mackenzie and J. Wajcman (eds) 1999 The Social Shaping of Technology, Second Edition, Buckingham, UK: Open University Press.) 2000a 'Organizing Alignment: A case of bridge-building', Organization 7(2): 311-27.

2000b 'Embodied Practices of Engineering Work', Mind, Culture and Activity 7 (1 and 2): 4-18.

__ 2000c "Making A Case: "Knowledge" and "Routine" work in document production', in P. Luff, J. Hindmarsh and C. Heath (eds) Workplace Studies, Cambridge: Cambridge University Press.

Suchman, L., Blomberg, J., Orr, J. and Trigg R. 1999 'Reconstructing Technologies as Social Practice', American Behavioral Scientist 43(3): 392-408.

Traweek, S. 1988 Beamtimes and Lifetimes: The world of high energy physicists, Cambridge, MA: Harvard University Press.

Yates, J. 1989 Control through Communication: The rise of system in American management, Baltimore and London: Johns Hopkins University Press. 